\title{
Comparison of Flow Injection MS, NMR, and DNA Sequencing: Methods for Identification and Authentication of Black Cohosh (Actaea racemosa)
}

Authors

Affiliations
James Harnly ${ }^{1}$, Pei Chen ${ }^{1}$, Jianghao Sun ${ }^{1}$, Huilian Huang ${ }^{1}$, Kimberly L. Colson ${ }^{2}$, Jimmy Yuk ${ }^{2}$, Joe-Ann H. McCoy ${ }^{3}$, Danica T. Harbaugh Reynaud ${ }^{4}$, Peter B. Harrington ${ }^{5}$, Edward J. Fletcher ${ }^{6}$

The affiliations are listed at the end of the article

\author{
Key words \\ - Actaea racemose \\ - Ranunculaceae \\ - NMR \\ - FIMS \\ - DNA sequencing
}

\begin{abstract}
$\nabla$

Flow injection mass spectrometry and proton nuclear magnetic resonance spectrometry, two metabolic fingerprinting methods, and DNA sequencing were used to identify and authenticate Actaea species. Initially, samples of Actaea racemosa from a single source were distinguished from other Actaea species based on principal component analysis and soft independent modeling of class analogies of flow injection mass spectrometry and proton nuclear magnetic resonance spectrometry metabolic fingerprints. The chemometric results for flow injection mass spectrometry and proton nuclear magnetic resonance spectrometry agreed well and showed similar agreement throughout the study. DNA sequencing us-
\end{abstract}

\section{Introduction}

received January 29,2015

revised Sept. 2, 2015

accepted Sept. 3, 2015

\section{Bibliography}

DOI http://dx.doi.org/ 10.1055/s-0035-1558113

Published online December 21, 2015

Planta Med 2016; 82: 250-262 (c) Georg Thieme Verlag KG Stuttgart · New York . ISSN 0032-0943

\section{Correspondence}

James M. Harnly

Food Composition and Methods Development Laboratory Beltsville Human Nutrition Research Center Agricultural Research Service U.S. Department of Agriculture 10300 Baltimore Ave, Building 161

Beltsville, MD 20705 USA

Phone: + 13015048569

Fax: + 13015048314

james.harnly@ars.usda.gov

\section{$\nabla$}

This study describes the application of two chemical fingerprinting methods and a genetic sequencing method for the authentication of black cohosh [Actaea racemosa L. (Ranunculaceae)], one of the top ten selling dietary supplements in the U.S. [1]. The three methods include flow injection mass spectrometry (FIMS), proton nuclear magnetic resonance $\left({ }^{1} \mathrm{H}-\mathrm{NMR}\right)$, and DNA sequencing using universal primer regions. A. racemosa is a particularly appropriate target botanical for this study as its increasing commercial demand has resulted in frequent adulteration and substitution for economic purposes.

Identification and authentication of botanical materials is a challenging task due to their complex chemistry, phylogeny, and numerous material forms which include dried plant material, ground powder, liquid extracts, and dried extracts. The gold standard for taxonomy is based on morphological characteristics from a whole plant, primarily of the flower and/or fruit by an expert botanist ing DNA sequence data from two independent gene regions confirmed the metabolic fingerprinting results. Differences were observed between $A$. racemosa samples from four different sources, although the variance within species was still significantly less than the variance between species. A model based on the combined A. racemosa samples from the four sources consistently permitted distinction between species. Additionally, the combined $A$. racemosa samples were distinguishable from commercial root samples and from commercial supplements in tablet, capsule, or liquid form. DNA sequencing verified the lack of authenticity of the commercial roots but was unsuccessful in characterizing many of the supplements due to the lack of available DNA.

[2]. Even this approach, however, has its limitations, as plant material received for commercial production may not match the original voucher specimen or may contain organs or plant parts that aren't typically used for taxonomic identification (i.e., roots). Macroscopic and microscopic methods have also been used extensively, but as raw plant materials are ground and extracted, qualitative methods become less applicable. Ground botanical materials lose their morphological characteristics but can retain their genetic identity. As a result, DNA sequencing is becoming an increasingly routine and affordable method for taxonomic discrimination of ground plant materials.

Identification of extracted botanical materials can be highly problematic. Extraction targets broad groups of compounds based on the polarity of the solvent and is frequently used for enrichment of desirable components and/or removal of undesirable components. Consequently, extraction will alter the chemical composition of a botanical as compared to the original solid material. Extrac- 
tion can also be problematic for DNA sequencing. The availability of sufficient lengths of DNA sequences is highly dependent on the extraction technique and the DNA sequencing method.

One of the most comprehensive approaches to botanical authentication based on chemical composition is metabolic fingerprinting. Hall [3] defined metabolic fingerprinting as "High throughput qualitative screening of the metabolic composition of an organism or tissue with the primary aim of sample comparison and discrimination analysis. Generally no attempt is initially made to identify the metabolites present. All steps from sample preparation, separation, and detection should be rapid and as simple as is feasible". Chromatographic and spectral (with no prior separation) fingerprinting can meet Hall's definition. Both approaches generate complex fingerprints that may require multivariate analysis for discrimination. A general approach to the validation of botanical identification methods using multivariate analysis has been described by AOAC International $[4,5]$.

Numerous methods have been developed and utilized for the authentication of A. racemosa [6-9], although none of them include chemical fingerprinting methods. The most commonly used methods rely on the identification and quantification of specific metabolites (chemical markers), an approach defined as metabolic profiling. Ma et al. [6] described a method based on highperformance liquid chromatography coupled with electrospray ionization/mass spectrometry (HPLC-ESI/MS) to identify 15 chemical markers. Qiu et al. [7] described a method using NMR for the measurement of triterpenes in A. racemosa. The two-dimensional plots obtained from heteronuclear single-quantum coherence (HSQC) measurements (combining ${ }^{1} \mathrm{H}-\mathrm{NMR}$ and ${ }^{13} \mathrm{C}$-NMR) were used to generate patterns for distinguishing the various Actaea species. Neither of these methods are comprehensive because they depended solely on identified components and ignore the bulk of the components observed in the MS and NMR spectra. Furthermore, neither study validated the markers by measuring identification rates.

In previous studies, Harnly's lab [10-15] has demonstrated the use of spectral fingerprints obtained by IR, NIR, FIMS (with both positive and negative ionization), and UV spectrometry for characterizing botanicals (bitter orange, black cohosh, Ginkgo, and ginseng) and food plants and materials (broccoli, dry beans, grapefruit, skim milk powder). Spectral fingerprinting allowed for the discrimination between species, growing locations, growing conditions, and processing. FIMS proved to be a particularly useful method [14-16]. Whereas chromatographic methods require special care for retention time alignment, normal mass calibration procedures for nominal and high-resolution FIMS provide suitably stable fingerprints. The advantages of FIMS are the excellent sensitivities and potential for identifying discriminating components (especially with high-resolution FIMS) from the variable loadings obtained from the chemometric models. However, ion counts are highly dependent on the ionization process and reproducibility between experiments on the same instrument and between different instrument designs can be poor. This generally necessitates a batch type of operation, i.e., fingerprints can only be compared between new and reference samples analyzed under the same conditions and at the same time. This process rapidly depletes the supply of reference samples.

NMR, by comparison, has not been used as frequently for spectral fingerprinting, although several excellent studies have been reported [17-21]. In general, NMR may be considered less sensitive than MS, more expensive with respect to cost and consumables, and requires an extra sample preparation step of drying and re- constitution in a deuterated solvent. However, its inherent stability makes it an excellent candidate for fingerprinting, allowing the possibility of simply comparing spectra of new materials with archived spectra to determine authenticity. Like MS, the NMR spectra provide the added possibility of identifying specific components that provide sample discrimination. In addition, the uniform response of ${ }^{1} \mathrm{H}$-NMR facilitates calibration and allows for the quantification of compounds.

Fingerprint comparisons of FIMS and NMR spectra are assisted by multivariate analysis methods. There are two general approaches: modeling (a soft method) and classification (a hard method). Soft models, such as the soft independent modeling of class analogy (SIMCA) [22] and the fuzzy optimal associative memory (FOAM) [23], fit a model to a single class. They are also referred to as one-class classifiers because they model the similarities among features of the spectra within just a single class. As a result, they are a useful tool for authentication. A set of authentic objects is used to construct a model that is used to judge whether the test samples are authentic or not. Compared to classification methods, modeling methods tend to have less discriminating power. However, they have the advantage of being able to reject novel spectral fingerprints with characteristics not included in the model.

Hard models, or classification methods, such as the partial least squares-discriminant analysis (PLS-DA) [24] and the fuzzy rulebuilding expert system (FuRES) [25], require identification of every class to be considered in the model and force an unknown sample into one of the classes. PLS-DA builds harder models as the number of components increase. FuRES is a soft classification method by its fuzzy constraints. Classification works well when the classes of samples are well known and potential adulterants are known ahead of time. Classification models will typically misclassify new fingerprints that do not belong to any of the classes, i.e., have features not incorporated into the model.

A third method that can be used for authentication is DNA sequencing, which uses universal gene regions to identify organisms [26]. Like metabolic fingerprinting, the pattern of the sequence is matched with reference sequences to authenticate the botanical identity. DNA sequencing provides a genotypic fingerprint, not a metabolic fingerprint. The "DNA barcode", which the DNA sequence is often referred as, is complementary to metabolic fingerprinting, allowing for the identification of species and, in some cases, subspecies or variety. It is not appropriate for discriminating between plant parts or the influence of the environment on metabolite expression. As the cost of DNA sequencing drops, it is becoming the method of choice for the authentication of raw animal and plant materials. For finished product supplements, the method may be inappropriate as the absence of DNA, or presence of low quality DNA, is problematic [27]. However, new sequencing methods are being developed with more species-specific primers that target short fragments of DNA as would be expected in finished products [28].

The purpose of this study was to examine the ability of NMR and FIMS, in combination with multivariate analysis, to discriminate between Actaea species, between raw materials and commercial products, and to compare spectral classification with DNA sequencing. First, FIMS and ${ }^{1} \mathrm{H}-\mathrm{NMR}$ fingerprints of Actaea species obtained from a single source were compared using principal component analysis (PCA) and SIMCA. Identification of the species was confirmed using DNA sequencing based on two independent nuclear ribosomal and chloroplast gene regions as validated for Actaea [29]. Samples of authentic Actaea species from 
Table 1 American Herbal Pharmacopoeia samples.

\begin{tabular}{|c|c|c|c|c|c|c|c|c|c|c|}
\hline ID \# & Species & Part & Form & Source & Location & nrDNA & Mix & Hybrid & cPDNA & Mix \\
\hline \multicolumn{11}{|c|}{ American Herbal Pharmacopoeia } \\
\hline BCR01 & A. racemosa & $r / r$ & powder & AHP & North Carolina & A. racemosa & yes & $\mathrm{n} / \mathrm{a}$ & A. racemosa & no \\
\hline BCR02 & A. pachypoda & $r / r$ & powder & AHP & North Carolina & A. pachypoda & no & no & A. pachypoda & no \\
\hline BCR03 & A. racemosa & $r / r$ & powder & AHP & China & A. pachypoda & no & no & pqs & $\mathrm{n} / \mathrm{a}$ \\
\hline BCR04 & A. racemosa & $r / r$ & powder & $\mathrm{AHP}$ & New Jersey & A. racemosa & little & no & A. racemosa & no \\
\hline BCR05 & A. pachypoda & $r / r$ & powder & $\mathrm{AHP}$ & North Carolina & A. pachypoda & no & no & A. pachypoda & no \\
\hline BCR06 & A. racemosa & $r / r$ & powder & AHP & NA & A. racemosa & no & maybe & A. racemosa & no \\
\hline BCR07 & A. racemosa & $r / r$ & powder & $\mathrm{AHP}$ & North Carolina & A. racemosa & little & maybe & No ID & yes \\
\hline BCR08 & A. racemosa & $r / r$ & powder & AHP & North Carolina & A. racemosa & little & maybe & No ID & yes \\
\hline BCR09 & A. racemosa & $r / r$ & powder & AHP & North Carolina & A. racemosa & no & maybe & A. racemosa & no \\
\hline BCR10 & A. podocarpa & $r / r$ & powder & AHP & North Carolina & A. podocarpa & no & no & A. podocarpa & no \\
\hline BCR11 & A. podocarpa & $r / r$ & powder & AHP & North Carolina & A. podocarpa & no & no & A. podocarpa & no \\
\hline BCR12 & A. podocarpa & $r / r$ & powder & AHP & North Carolina & A. podocarpa & no & no & A. podocarpa & no \\
\hline BCR13 & A. cimcifuga & $r / r$ & powder & AHP & China & A. dahurica & no & no & A. dahurica & no \\
\hline BCR14 & A. rubra & $r / r$ & powder & AHP & Quebec, Canada & A. rubra & no & yes & A. pachypoda & no \\
\hline BCR15 & A. rubra & $r / r$ & powder & AHP & Oregon & A. rubra & no & no & A. rubra & no \\
\hline BCR16 & A. racemosa & $r / r$ & powder & AHP & commercial & A. racemosa & no & maybe & A. racemosa & no \\
\hline BCR17 & A. racemosa & $r / r$ & powder & AHP & commercial & A. racemosa & no & maybe & A. racemosa & no \\
\hline BCR18 & A. cimcifuga & $r / r$ & powder & AHP & commercial & Erotium & yes & $\mathrm{n} / \mathrm{a}$ & No ID & $\mathrm{n} / \mathrm{a}$ \\
\hline BCR19 & A. cimcifuga & $r / r$ & powder & AHP & China & Erotium & yes & $\mathrm{n} / \mathrm{a}$ & No ID & yes \\
\hline BCR20 & A. cimcifuga & $r / r$ & powder & AHP & China & Erotium & yes & $\mathrm{n} / \mathrm{a}$ & No ID & yes \\
\hline BCR21 & A. cimcifuga & $r / r$ & powder & AHP & commercial & Erotium & yes & $\mathrm{n} / \mathrm{a}$ & No ID & $\mathrm{n} / \mathrm{a}$ \\
\hline BCR22 & A. cimcifuga & $r / r$ & powder & AHP & commercial & A. dahurica & yes & $\mathrm{n} / \mathrm{a}$ & A. dahurica & no \\
\hline BCR23 & A. cimcifuga & $r / r$ & powder & AHP & China & A. dahurica & yes & $\mathrm{n} / \mathrm{a}$ & A. dahurica & no \\
\hline BCR24 & A. cimcifuga & $r / r$ & powder & AHP & China & A. dahurica & yes & $\mathrm{n} / \mathrm{a}$ & A. dahurica & no \\
\hline
\end{tabular}

nrDNA: nuclear ribosomal DNA; cpDNA: chloroplast DNA; r/r: roots/rhizomes; n/a: not analyzed; pqs: poor quality sequence; NA: not available

Table 2 National Institute of Standards and Technology and Strategic Sources samples.

\begin{tabular}{|c|c|c|c|c|c|c|c|c|c|c|}
\hline ID \# & Species & Part & Form & Source & Location & nrDNA & Mix & Hybrid & cPDNA & Mix \\
\hline \multicolumn{11}{|c|}{ National Institute of Standards and Technology } \\
\hline SRM3295 & A. racemosa & $r / r$ & powder & NIST & NA & A. racemosa & yes & no & A. racemosa & yes \\
\hline SRM3296 & A. racemosa & $r / r$ & powder & NIST & NA & & & & & \\
\hline SRM3297 & A. racemosa & $r / r$ & powder & NIST & NA & & & & & \\
\hline SRM3298 & A. racemosa & $r / r$ & powder & NIST & NA & & & & & \\
\hline \multicolumn{11}{|c|}{ Strategic Sources } \\
\hline SS01 & A. racemosa & $r / r$ & $r / r$ & SS & Madison, AL & A. racemosa & no & maybe & A. racemosa & no \\
\hline SSO2 & A. racemosa & $r / r$ & $r / r$ & SS & Bell, KT & A. racemosa & no & maybe & A. racemosa & no \\
\hline SS03 & A. racemosa & $r / r$ & $r / r$ & SS & Logan, WV & A. racemosa & yes & $\mathrm{n} / \mathrm{a}$ & A. racemosa & no \\
\hline SSO4 & A. racemosa & $r / r$ & $r / r$ & SS & Carter, MO & A. racemosa & yes & $\mathrm{n} / \mathrm{a}$ & A. racemosa & no \\
\hline SS05 & A. racemosa & $r / r$ & $r / r$ & SS & Washington, MO & A. racemosa & yes & maybe & A. racemosa & no \\
\hline SS06 & A. racemosa & $r / r$ & $r / r$ & SS & Clay, KT & A. racemosa & no & no & A. racemosa & no \\
\hline SS07 & A. racemosa & $r / r$ & $r / r$ & SS & Pike, KT & A. racemosa & yes & maybe & A. racemosa & no \\
\hline
\end{tabular}

nrDNA: nuclear ribosomal DNA; cpDNA: chloroplast DNA; r/r: roots/rhizomes; n/a: not analyzed; NA: not available

multiple sources were then examined using FIMS, ${ }^{1} \mathrm{H}-\mathrm{NMR}$, and DNA sequencing and compared to the supplier's identification. Similarly, metabolic fingerprints and DNA sequences were used to compare authentic $A$. racemosa samples with both commercially available root samples and with commercially available supplements. Four multivariate methods (SIMCA FOAM, PLS-DA, and FuRES) were used to evaluate the data in this study.

\section{Results and Discussion}

$\nabla$

MS and NMR spectra were acquired for the Actaea species listed in Tables 1-4. Typical spectra for $A$. racemosa are given in - Fig. 1. The FIMS spectra were acquired with flow injection (no separation) for $m / z 150$ to 1500 . The NMR spectra were acquired from -3.0 to $16.0 \mathrm{ppm}$, but only the region from 0.5 to $9.0 \mathrm{ppm}$ was used in this study. The top spectra of $\bullet$ Fig. 1 have not undergone any preprocessing. The bottom plots show both spectra after normalization to unit vector length and autoscaling with respect to the A. racemosa spectra. The NMR spectra had the DMSO solvent peak at $2.53 \mathrm{ppm}$ removed before the preprocessing steps. The solvent peak can potentially introduce added undesirable variance to the data and may confound classification and modeling, although this was not the case (data not shown).

The initial goal was to compare the ability of FIMS and NMR to discriminate between species. Because the PCA of the spectra for all the samples in $\bigcirc$ Tables $\mathbf{1 - 4}$ produced very complex score plots that were difficult to interpret, a reductionist approach was deemed necessary for this phase of the investigation. Consequently, only spectra for A. racemosa and four other Actaea spe- 
Table 3 The North Carolina Arboretum Germplasm Repository samples.

\begin{tabular}{|c|c|c|c|c|c|c|c|c|c|c|}
\hline ID \# & Species & Part & Form & Source & Location & nrDNA & Mix & Hybrid & cpDNA & Mix \\
\hline NCC1 & A. racemosa & $r / r$ & powder & NCA & composite 2 & A. racemosa & no & no & A. racemosa & no \\
\hline NCC2 & A. racemosa & $r / r$ & powder & NCA & composite 2 & A. racemosa & no & no & A. racemosa & no \\
\hline NC01a & A. racemosa & $r / r$ & powder & NCA & NC & & & & & \\
\hline NC01b & A. racemosa & $r / r$ & powder & NCA & NC & & & & & \\
\hline NC01C & A. racemosa & $r / r$ & powder & NCA & NC & & & & & \\
\hline NC02a & A. racemosa & $r / r$ & powder & NCA & VA & & & & & \\
\hline $\mathrm{NCO2b}$ & A. racemosa & $r / r$ & powder & NCA & VA & & & & & \\
\hline $\mathrm{NCO2C}$ & A. racemosa & $r / r$ & powder & NCA & VA & & & & & \\
\hline NC03a & A. racemosa & $r / r$ & powder & NCA & PA & & & & & \\
\hline NC03b & A. racemosa & $r / r$ & powder & NCA & PA & & & & & \\
\hline $\mathrm{NCO3C}$ & A. racemosa & $r / r$ & powder & NCA & PA & & & & & \\
\hline NC04a & A. racemosa & $r / r$ & powder & NCA & NY & & & & & \\
\hline NC04b & A. racemosa & $r / r$ & powder & NCA & NY & & & & & \\
\hline $\mathrm{NCO} 4 \mathrm{C}$ & A. racemosa & $r / r$ & powder & NCA & NY & & & & & \\
\hline NC05a & A. racemosa & $r / r$ & powder & NCA & AR & & & & & \\
\hline NC05b & A. racemosa & $r / r$ & powder & NCA & AR & & & & & \\
\hline NC05c & A. racemosa & $r / r$ & powder & NCA & AR & & & & & \\
\hline NC06a & A. racemosa & $r / r$ & powder & NCA & $\mathrm{MO}$ & & & & & \\
\hline NC06b & A. racemosa & $r / r$ & powder & NCA & MO & & & & & \\
\hline NC06C & A. racemosa & $r / r$ & powder & NCA & MO & & & & & \\
\hline NC07a & A. racemosa & $r / r$ & powder & NCA & WV & & & & & \\
\hline NC08a & A. racemosa & $r / r$ & powder & NCA & WV & & & & & \\
\hline NC08b & A. racemosa & $r / r$ & powder & NCA & WV & & & & & \\
\hline NC08c & A. racemosa & $r / r$ & powder & NCA & WV & & & & & \\
\hline NC09a & A. racemosa & $r / r$ & powder & NCA & WV & & & & & \\
\hline NC09b & A. racemosa & $r / r$ & powder & NCA & WV & & & & & \\
\hline NC09c & A. racemosa & $r / r$ & powder & NCA & WV & & & & & \\
\hline NC10a & A. racemosa & $r / r$ & powder & NCA & VA & & & & & \\
\hline NC11a & A. racemosa & $r / r$ & powder & NCA & TN & & & & & \\
\hline NC11b & A. racemosa & $r / r$ & powder & NCA & TN & & & & & \\
\hline NC11c & A. racemosa & $r / r$ & powder & NCA & TN & & & & & \\
\hline NC12a & A. racemosa & $r / r$ & powder & NCA & PA & & & & & \\
\hline $\mathrm{NC12b}$ & A. racemosa & $r / r$ & powder & NCA & $\mathrm{PA}$ & & & & & \\
\hline $\mathrm{NC} 12 \mathrm{C}$ & A. racemosa & $r / r$ & powder & NCA & PA & & & & & \\
\hline NC13a & A. racemosa & $r / r$ & powder & NCA & NY & & & & & \\
\hline NC13b & A. racemosa & $r / r$ & powder & NCA & NY & & & & & \\
\hline NC13C & A. racemosa & $r / r$ & powder & NCA & NY & & & & & \\
\hline NC14a & A. racemosa & $r / r$ & powder & NCA & NC & & & & & \\
\hline NC14b & A. racemosa & $r / r$ & powder & NCA & NC & & & & & \\
\hline NC14c & A. racemosa & $r / r$ & powder & NCA & NC & & & & & \\
\hline NC15a & A. racemosa & $r / r$ & powder & NCA & NC & & & & & \\
\hline NC15b & A. racemosa & $r / r$ & powder & NCA & NC & & & & & \\
\hline NC15c & A. racemosa & $r / r$ & powder & NCA & NC & & & & & \\
\hline NC16a & A. racemosa & $r / r$ & powder & NCA & NC & & & & & \\
\hline NC16b & A. racemosa & $r / r$ & powder & NCA & NC & & & & & \\
\hline NC16c & A. racemosa & $r / r$ & powder & NCA & NC & & & & & \\
\hline NC18a & A. racemosa & $r / r$ & powder & NCA & $\mathrm{MD}$ & & & & & \\
\hline NC19a & A. racemosa & $r / r$ & powder & NCA & KY & & & & & \\
\hline NC19b & A. racemosa & $r / r$ & powder & NCA & KY & & & & & \\
\hline NC20a & A. racemosa & $r / r$ & powder & NCA & IN & & & & & \\
\hline NC20b & A. racemosa & $r / r$ & powder & NCA & IN & & & & & \\
\hline NC20c & A. racemosa & $r / r$ & powder & NCA & IN & & & & & \\
\hline NC21a & A. racemosa & $r / r$ & powder & NCA & $\mathrm{DE}$ & & & & & \\
\hline NC21b & A. racemosa & $r / r$ & powder & NCA & $\mathrm{DE}$ & & & & & \\
\hline NC21c & A. racemosa & $r / r$ & powder & NCA & $\mathrm{DE}$ & & & & & \\
\hline NC22a & A. racemosa & $r / r$ & powder & NCA & $\mathrm{DE}$ & & & & & \\
\hline
\end{tabular}

nrDNA: nuclear ribosomal DNA; cpDNA: chloroplast DNA; r/r: roots//hizomes

cies [Actaea cimicifuga L., Actaea pachypoda Ell., Actaea podocarpa DC., and Actaea rubra (Aiton) Willd.] purchased from AHP ( Table 1) were submitted to PCA and SIMCA. The same samples were submitted to PCA and SIMCA so that the FIMS and NMR results may be compared.
- Fig. 2 comprises PCA score plots and SIMCA influence plots obtained by FIMS in the left column and NMR in the right column. There are strong similarities between the responses of the two methods as can be seen by the PCA scores. For both instruments: 1) the A. racemosa clustered separately from the other species, 2) 
Table 4 Commercial roots and supplements.

\begin{tabular}{|c|c|c|c|c|c|c|c|c|c|c|}
\hline ID \# & Species & Part & Form & Source & Location & nrDNA & Mix & Hybrid & cpDNA & Mix \\
\hline CA01 & A. racemosa & $r / r$ & $r / r$ & - & Liaoning, China & A. dahurica & yes & $\mathrm{n} / \mathrm{a}$ & A. dahurica & no \\
\hline CA02 & A. heracleifolia & $r / r$ & $r / r$ & - & Heilongjiang, China & A. dahurica & yes & $\mathrm{n} / \mathrm{a}$ & No ID & yes \\
\hline CA03 & A. heracleifolia & $r / r$ & $r / r$ & - & Sichuan, China & Acanthaceae & no & $\mathrm{n} / \mathrm{a}$ & Baphicacanthus & no \\
\hline CA04 & A. foetida & $r / r$ & $r / r$ & - & Hebei, China & Eurotium sp. & yes & $\mathrm{n} / \mathrm{a}$ & No ID & $\mathrm{n} / \mathrm{a}$ \\
\hline CA05 & A. foetida & $r / r$ & $r / r$ & - & suzhou,China & A. dahurica & yes & $\mathrm{n} / \mathrm{a}$ & A. dahurica & no \\
\hline CA06 & A. dahurica & $r / r$ & $r / r$ & - & Hebei, China & No ID & yes & $\mathrm{n} / \mathrm{a}$ & A. dahurica & yes \\
\hline CA07 & A. dahurica & $r / r$ & $r / r$ & - & Sichuan, China & Pichia sp. & yes & $\mathrm{n} / \mathrm{a}$ & A. dahurica & no \\
\hline CA08 & A. dahurica & $r / r$ & $r / r$ & - & North Korea & A. dahurica & yes & no & A. dahurica & no \\
\hline CA09 & A. foetida & $r / r$ & $r / r$ & - & North Korea & A. brachycarpa & yes & no & A. brachycarpa & no \\
\hline CA10 & A. foetida & $r / r$ & $r / r$ & - & Yunnan, China & A. dahurica & yes & yes & A. dahurica & no \\
\hline CA11 & A. foetida & $r / r$ & $r / r$ & - & Henan, China & A. dahurica & yes & yes & A. dahurica & yes \\
\hline CA12 & Vernonia aspera & $r / r$ & $r / r$ & - & Hebei, China & Eupatorium & no & $\mathrm{n} / \mathrm{a}$ & E. fortunei & no \\
\hline CA13 & V. aspera & $r / r$ & $r / r$ & - & Yunnan, China & Astereae & yes & $\mathrm{n} / \mathrm{a}$ & E. fortunei & no \\
\hline CA14 & V. aspera & $r / r$ & $r / r$ & - & Yunnan, China & & & & & \\
\hline CS01 & A. racemosa & - & tab & & NA & & & & & \\
\hline $\mathrm{CSO} 2$ & A. racemosa & - & tab & & NA & & & & & \\
\hline $\mathrm{CS} 03$ & A. racemosa & - & liq & & NA & & & & & \\
\hline $\mathrm{CS} 04$ & A. racemosa & - & liq & & NA & & & & & \\
\hline CS05 & A. racemosa & - & liq & & NA & & & & & \\
\hline CS06 & A. racemosa & - & liq & & NA & & & & & \\
\hline $\mathrm{CSO}$ & A. racemosa & - & liq & & NA & & & & & \\
\hline $\mathrm{CS} 08$ & A. racemosa & - & cap & & NA & A. racemosa & no & no & A. racemosa & no \\
\hline CS09 & A. racemosa & - & cap & & NA & A. racemosa & no & no & A. racemosa & no \\
\hline CS10 & A. racemosa & - & cap & & $?$ & A. racemosa & no & no & A. racemosa & no \\
\hline CS11 & A. racemosa & - & cap & & $?$ & no DNA & $\mathrm{n} / \mathrm{a}$ & no & no DNA & $\mathrm{n} / \mathrm{a}$ \\
\hline CS12 & A. racemosa & - & cap & & $?$ & A. brachycarpa & no & no & pqs & $\mathrm{n} / \mathrm{a}$ \\
\hline CS13 & A. racemosa & - & cap & & $?$ & A. racemosa & yes & no & pqs & $\mathrm{n} / \mathrm{a}$ \\
\hline CS14 & A. racemosa & - & cap & & $?$ & Oryza sativa & yes & $\mathrm{n} / \mathrm{a}$ & O. sativa & no \\
\hline
\end{tabular}

nrDNA: nuclear ribosomal DNA; cpDNA: chloroplast DNA; r/r: roots/rhizomes; n/a: not analyzed; pqs: poor quality sequence; NA: not available; tab: tablet; liq: liquid; cap: capsule
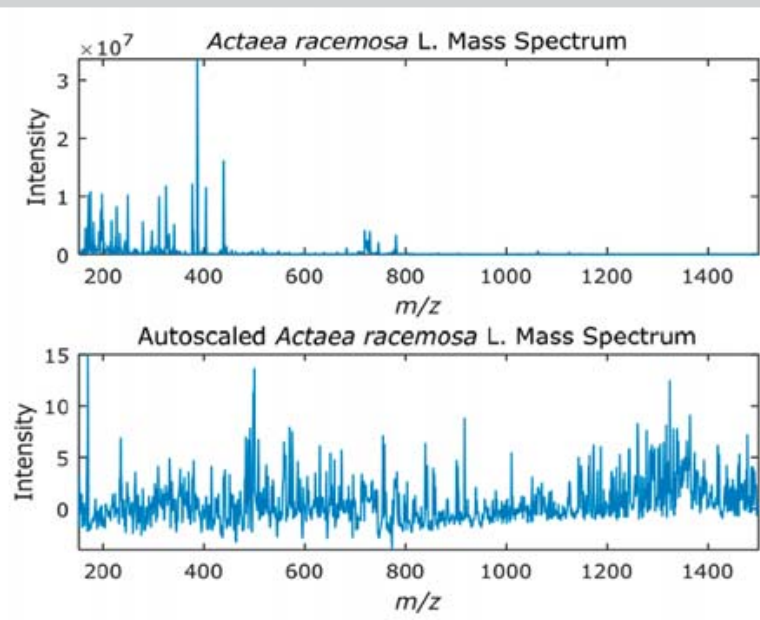

Fig. 1 Comparison of $A$. racemosa spectra before and after preprocessing, which comprised normalization to unit length followed by autoscaling to the
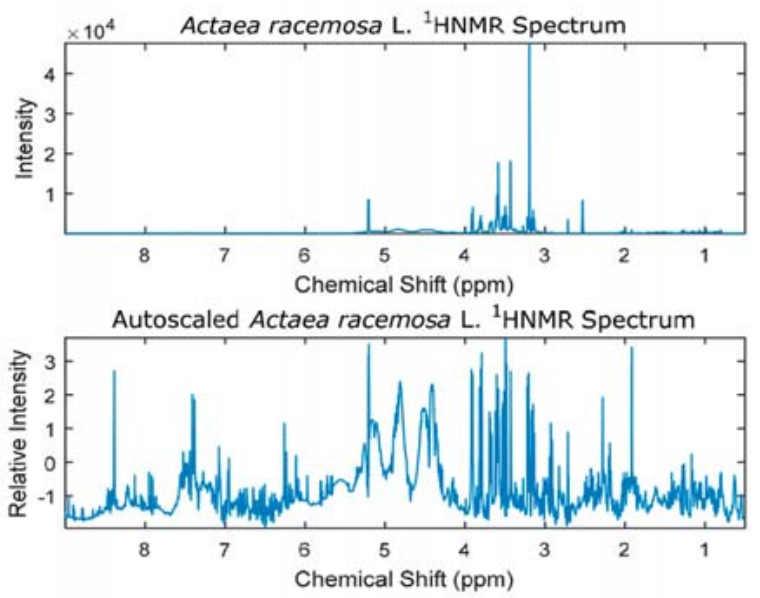

sample BCR02, identified by AHP as A. pachypoda, appears in the $A$. racemosa, cluster, and 3 ) sample BCR16, identified by AHP as A. racemosa, appears outside the $A$. racemosa cluster. Samples BCR02 and BCR16 were analyzed twice by NMR two months apart; the repeat analyses agreed well with the original analyses. In general, the discrimination between the Actaea species provided by the two methods is in close agreement.
A. racemosa species. For the NMR, the DMSO solvent peak was removed at 2.54 ppm before preprocessing. (Color figure available online only.)
The influence plots (i.e., $Q$ statistic plotted as a function of the Hotelling $T^{2}$ statistic) are given at the bottom of 0 Fig. 2 for the FIMS and NMR data, respectively, for single component SIMCA models based on A. racemosa identified in $\odot$ Table 1. The $T^{2}$ and $Q$ statistics provide the variance accounted for by the SIMCA model and the residual variance unaccounted for by the model, respectively. In both cases, preprocessing consisted of normalization and autoscaling. For both instruments, the models for 

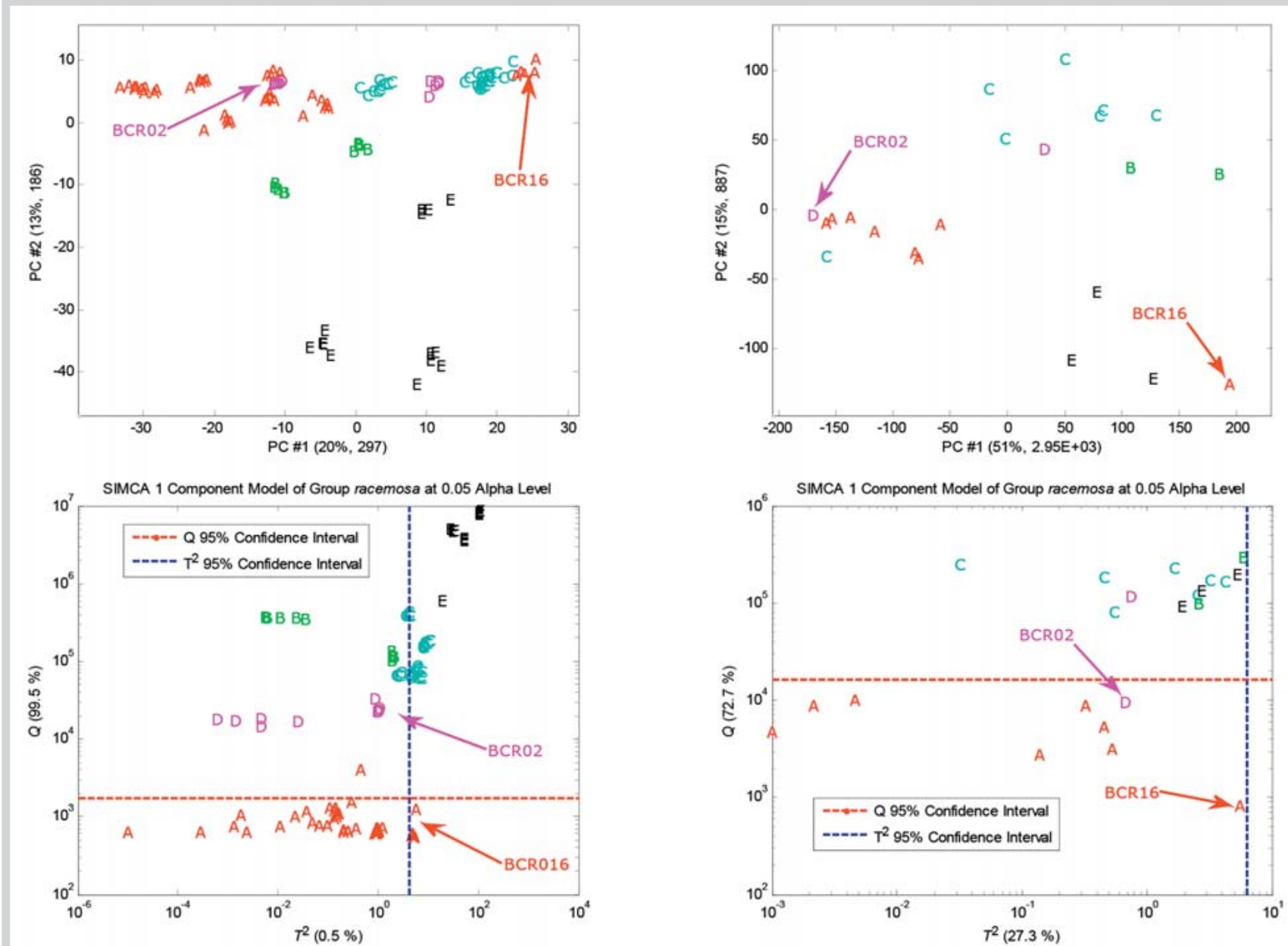

Fig. 2 Top left, scores of the preprocessed mass spectra; bottom left, one component SIMCA influence plot based on the AHP A. racemosa spectra. Top right, scores of the preprocessed NMR spectra; bottom right, one compo- nent SIMCA influence plot of the same samples at the mass spectra. A (red) A. racemosa, B (green) A. rubra, C (cyan) A. cimicifuga, D (magenta) A. pachypoda, $\mathbf{E}$ (black) A. podocarpa. (Color figure available online only.)
A. racemosa included sample BCR16, even though it did not cluster with the other A. racemosa scores in the PCA plots. The SIMCA models were based on one principal component, and the autoscale mean and standard deviations were only calculated from the set of $A$. racemosa spectra.

It is not appropriate to use influence plots without validation. Models are traditionally validated using bootstrapping. However, the limited number of samples in this phase of the project makes bootstrapping problematic. Dropping a single sample from the NMR data or a set of five repeats for a single sample from the FIMS data can produce dramatically different results. Still, the results for bootstrapping showed sensitivities of $91.4 \%$ and $91.7 \%$ for FIMS and NMR, respectively (data not shown). The specificities were $100.0 \%$ for both methods.

The results in Fig. 2 show the close agreement of the models based on the FIMS and NMR spectral fingerprinting and show that both are highly sensitive to changes in the sample chemical composition. Both methods can discriminate between the five Actaea species. Thus, for the purpose of identification and authentication, both FIMS and NMR perform equally well.

The third method used to characterize the Actaea species was DNA sequencing. Barcodes were determined at two loci: one nuclear ribosomal (nrDNA) and one chloroplast DNA (cpDNA). The
nrDNA were examined to determine if there was a mixture of DNA (contamination) or if the DNA represented a hybrid (species interbreeding). The cpDNA was also used to look for mixtures. Results for the DNA sequencing are presented in 0 Tables 1-4.

In general, DNA sequencing confirmed the species identification provided by AHP (Table 1 ). The exceptions were samples BCR03 and BCR18-BCR24. In each case, identification was complicated by the purity of the material. BCR03 was identified as A. pachypoda using nrDNA, but gave a poor quality sequence (PQS) with cpDNA. Samples BCR18 to BCR21 appeared moldy upon visual examination and were identified as the fungus Erotium by nrDNA. Both loci (nrDNA and cpDNA) indicated a mixture of DNA materials. BCR21 to BCR24 were identified as Actaea dahurica (Turcz. ex Fisch. \& C.A.Mey.) Franch. and not A. cimicifuga. Previously, next generation sequencing of SRM 3295 A. racemosa Rhizome had revealed that $2 \%$ of the DNA present was fungal [29]. Eurotium herbariorum, for example, was found in SRM 3295 and is a soil born fungus that is frequently found on dried plant products and is common in stored seeds. Thus, identification of BCR18 to BCR21 as the Eurotium genus is not surprising. These results do not preclude that $A$. cimicifuga is present in samples BCR18 to BCR21. The other samples in this study were not analyzed using next generation sequencing, which is unfortunate 


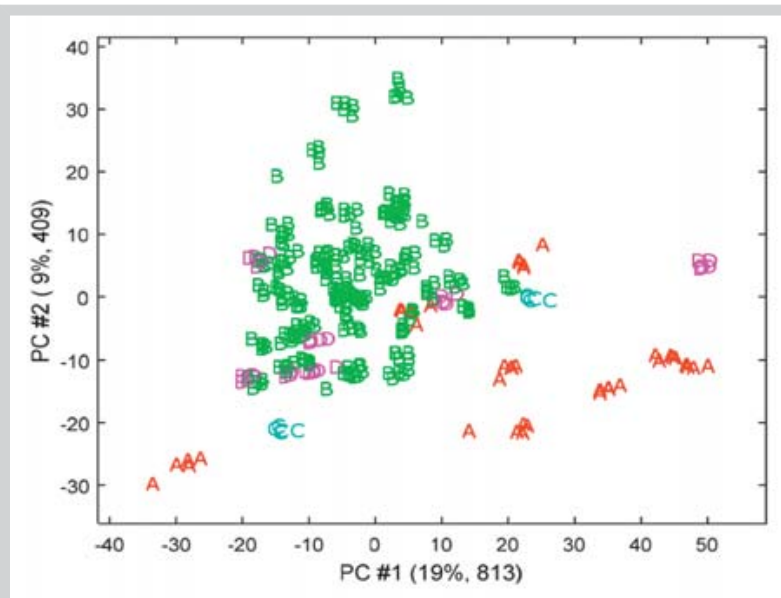

Fig. 3 Left, PCA scores of preprocessed A. racemosa mass spectra with respect to the different suppliers; right, PCA scores of preprocessed $A$. racemosa NMR spectra; right bottom, corresponding influence plot for a one component SIMCA model of the NMR spectra. A (red) American Herbal

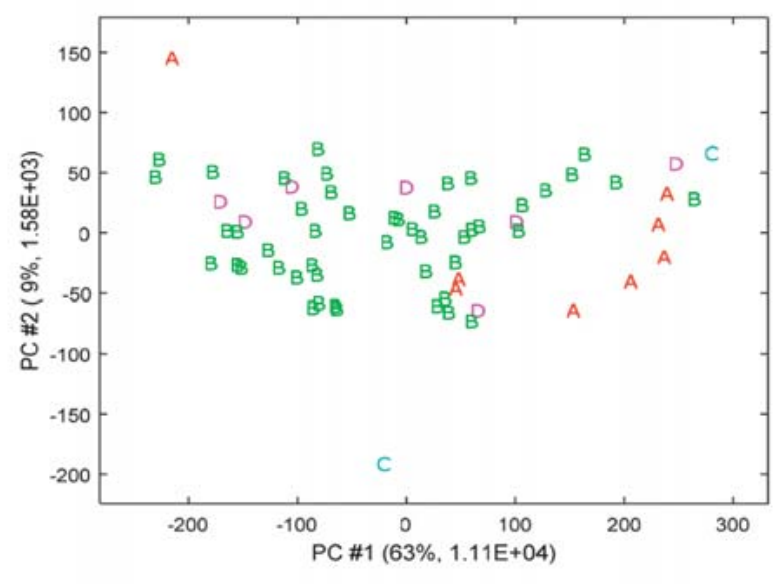

Pharmacopoeia, B (green) North Carolina Arboretum, C (cyan) National Institutes of Standards, D (magenta) Strategic Sources. (Color figure available online only.) because understanding the level of fungal load may be a significant factor in interpreting the chemical profiles.

Interestingly, samples BCR02 and BCR16, which appeared to be in the wrong clusters in $\odot$ Fig. 2 , were in fact accurately identified as A. pachypoda and A. racemosa, respectively, by DNA sequencing. The PCA scores in 0 Fig. 2 suggested that they were misidentified and led to the purchase of new samples from AHP. The new samples were analyzed by MS, NMR, and DNA sequencing, and produced the same results as initially obtained. The positions of BCR02 and BCR16 suggest that they contain components (or are missing components) that make them slightly different from the other samples of the same species. However, for both FIMS and NMR, the influence plots showed that the spectral fingerprints of BCR02 samples were closest to the other A. pachypoda samples, and fingerprints for BCR16 were closest to A. racemosa. These results emphasize the fact that these are complex biological samples and the phenotypes display far greater variation than the genotype.

As listed in Tables 1-3, authentic A. racemosa roots/rhizomes were obtained from four major sources. $\odot$ Fig. 3 comprises PCA score plots from spectra acquired by FIMS and NMR for A. racemosa samples from the American Herbal Pharmacopoeia (AHP), The North Carolina Arboretum Germplasm Repository (TNCAGR), Strategic Sources, Inc. (SSI), and the National Institute of Standards and Technology (SRM 3295, Black Cohosh Rhizome). TNCAGR furnished two composite $A$. racemosa materials that were used for method development and 55 samples collected from 22 sites from the east coast and as far west as Missouri.

The scores in the PCA plot in 8 Fig. 3 characterize the variation between the sources of the authentic A. racemosa samples. For MS, the differentiation of the sources is more apparent when incorporating the third principal component and viewed in three dimensions (score plot not shown). However, the distinction between sources was seen clearly by the NMR scores for the first two components. The samples were prepared independently for FIMS and run on the same day in a random order. When the FIMS and NMR are subjected to class modeling, the influence plots (using A. racemosa samples from AHP, TNCAGR, or SS as the class model) show specificities (fraction of the non-model samples identified as non-model) ranging from $75 \%$ to $99 \%$ (plots not shown). This indicates that the samples from the three sources are different from each other. Similarly, pooled ANOVA showed that the probability that the means of the three sources were the same was $<0.0001$ (data not shown).

The samples were prepared independently for FIMS and run on the same day in a random order. The same samples were dried, reconstituted in DMSO, and analyzed randomly by NMR. The agreement of the statistical analysis of the data from the two methods strongly suggests chemical differences between the different sources of authentic samples. These differences may arise from the geographic source of the samples (e.g., local genetic variations, different growth conditions, and/or different local pathogens) and/or systematic differences in post-harvest processing.

Metadata for the A. racemosa roots are presented in 0 Tables 1-3. Samples from TNCAGR and SSI were collected in the U.S. TNCAGR samples were originally harvested from native populations six years ago and cultivated under controlled conditions. All samples were harvested in October 2012. In general, most of the SS samples come from further west. The AHP samples come from a variety of sources across the U.S. as well as from Canada, China, and commercial sources. NIST SRM 3295 was obtained in bulk from a commercial source and the point of origin has not been disclosed. In most cases, the year of harvest is not available. DNA sequencing confirmed that the samples identified as $A$. racemosa by their supplier were genetically consistent with $A$. racemosa. The misidentification of one sample (BCR03) was discussed above. This sample was removed from the analyses.

Added insight into the variation within species can be gained by taking a closer look at the $A$. racemosa samples furnished by TNCAGR. Fig. 4 contains PCA score plots for those ten sites for which three samples were received (only one or two samples were received for the other five sites) and were analyzed by both FIMS and NMR. Both sets of profiles have a non-homogeneous distribution of the data from the different sites. The FIMS data demonstrate that the within site variance is considerably less than the between site variance and data from both methods demonstrate that the variance between sites is considerably less than the total variance for all sites. This was verified using pooled ANOVA. The probability that the means of the ten sites were sim- 


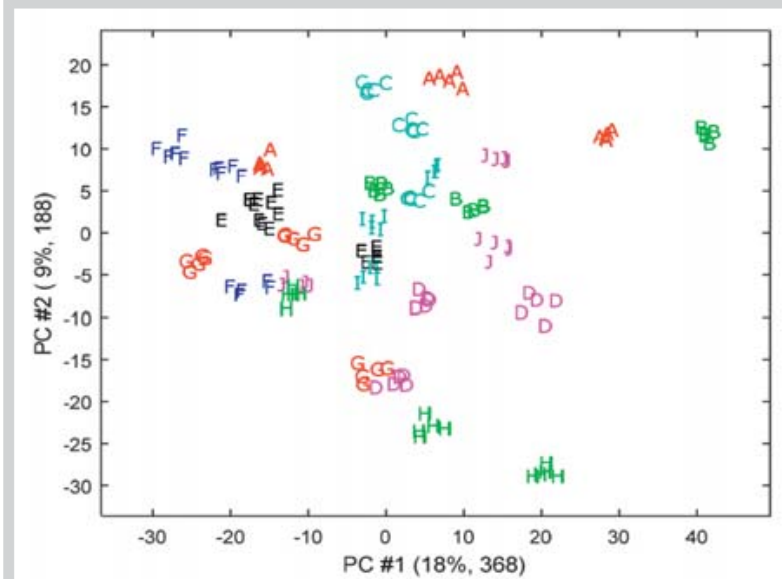

Fig. 4 Left, PCA scores of the preprocessed mass spectra with respect to 10 sites from the North Carolina Arboretum; right, PCA scores of the prepro-

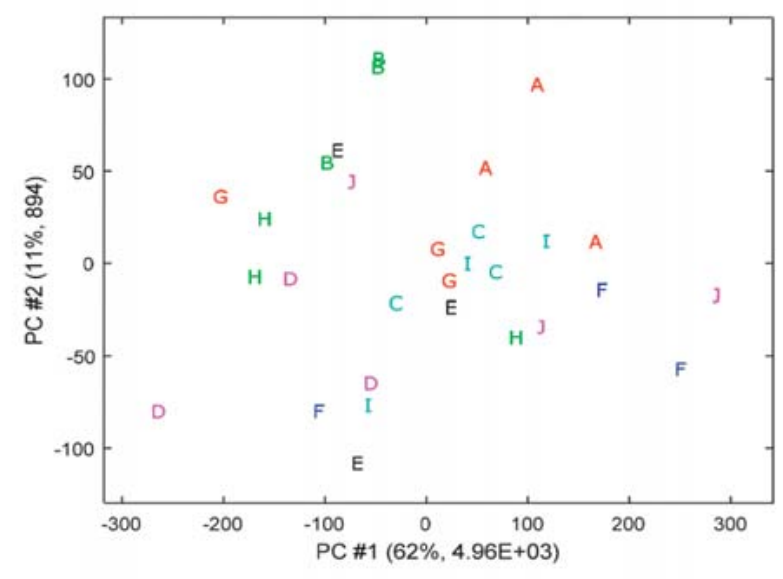

cessed NMR spectra with respect to the same 10 sites. (Each site has a different letter and color.) (Color figure available online only.)

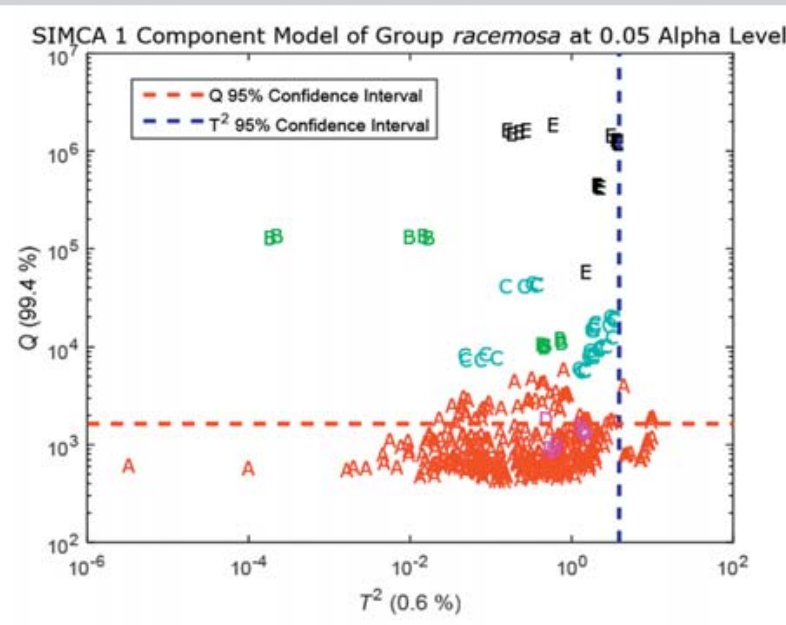

Fig. 5 Influence plots of the preprocessed mass (left) and NMR (right) spectra for the Actaea roots of the five species and all suppliers. A (red)

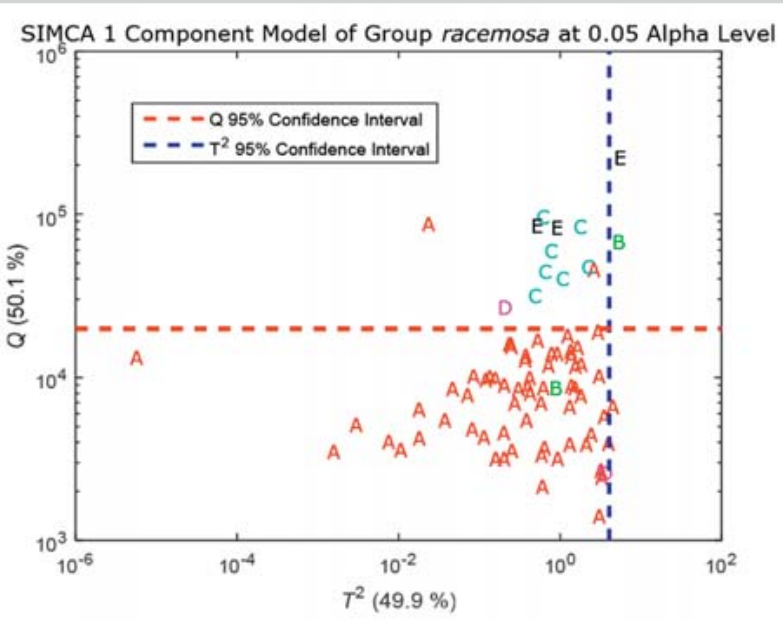

A. racemosa, B (green) A. rubra, C (cyan) A. cimicifuga, D (magenta) A. pachypoda, E (black) A. podocarpa. (Color figure available online only.) ilar was $<0.0001$ (data not shown). Thus, the individual sites provide subclusters within the $A$. racemosa cluster.

Differences in the chemical fingerprints of the $A$. racemosa samples from the 22 sites could arise from a number of sources. Environmental conditions (e.g., temperature, sunlight, rainfall, soil quality, and altitude) could be important factors. Post-harvest handling (e.g., drying conditions, shelf life, and storage temperatures) can influence enzymatic changes and long-term composition. Isolated plant colonies may also be subject to local genetic mutations. It has also been hypothesized that some of the purported health promoting chemical components of $A$. racemosa may come from endophytic fungi and not the plant itself [30]. Genetic mutation and endophytic fungi variation could potentially be major causes of variation between TNCAGR sites as all samples were grown under separate but similar conditions since their harvest from their original site six years ago. Future studies using second generation sequencing to determine the level of endophytic fungi will be informative.
- Fig. 5 presents the influence maps for a single component SIMCA model based on all of the A. racemosa samples using the FIMS and NMR spectra. 0 Fig. $\mathbf{5}$ is similar to 0 Fig. 2 influence plots, except the spectra from $A$. racemosa samples from all four sources are used for the class model to test the other four Actaea species obtained from AHP. The Q statistic is effective for differentiating $A$. racemosa from the other species with the exception of $A$. pachypoda for FIMS and A. rubra for NMR. There are a number of $A$. racemosa samples that fall above the confidence boundary.

As stated earlier, it is not appropriate to use influence plots without validation. Models are traditionally validated using independent sets of data. In this study, the $A$. racemosa fingerprints from 65 samples comprise the model building set of data and the 14 samples from the other species correspond to the negative spectra to evaluate the specificity of the model. To validate the model, the $65 \mathrm{~A}$. racemosa samples were randomly split into quarters so that $75 \%$ were used for constructing the model and the other $25 \%$ for evaluating the model. The FIMS data were randomly parti- 


\begin{tabular}{|llllll|}
\hline \multicolumn{3}{l}{ Modeling $(\boldsymbol{\alpha}=\mathbf{0 . 0 5})$} & \multicolumn{3}{l|}{ Classification } \\
Data set & Number & FOAM & SIMCA & FuRES & PLS-DA \\
\hline MS sensitivity & 324 & $96.7 \pm 0.2 \%$ & $91.1 \pm 0.2 \%$ & $98.2 \pm 0.3 \%$ & $95.4 \pm 0.3 \%$ \\
\hline MS specificity & 70 & $86.7 \pm 0.1 \%$ & $85.7 \pm 0.1 \%$ & $59.4 \pm 0.8 \%$ & $63.4 \pm 0.3 \%$ \\
\hline NMR sensitivity & 65 & $91.0 \pm 0.3 \%$ & $77.7 \pm 0.3 \%$ & $96.2 \pm 0.3 \%$ & $98.4 \pm 0.1 \%$ \\
\hline NMR specificity & 14 & $78.5 \pm 0.6 \%$ & $85.7 \pm 0.1 \%$ & $68.6 \pm 0.3 \%$ & $66.7 \pm 0.4 \%$ \\
\hline
\end{tabular}

Table 5 Modeling and classification results with $100 \times 4$ bootstrapped Latin partitions. tioned by samples, i.e., in multiples of five spectra. This procedure is comparable to the partitioning of the NMR data, which only consisted of a single spectrum per sample. For modeling, the sensitivity was determined as the fraction of $A$. racemosa samples that were correctly identified as $A$. racemosa. The specificity is the fraction of the other species that were correctly identified as not belonging to the $A$. racemosa model.

- Table 5 reports the validation results obtained using both class modeling and classification. For class modeling, SIMCA and FOAM (see Materials and Methods section) were compared using 100 bootstraps with four Latin partitions. Neither SIMCA nor FOAM were optimized in any way, but were used with standard parameters for all the evaluations with the exception that FOAM allowed the internal bootstrap validation to partition by sample to provide a better estimate of the residual error. While the same modification could have been made to SIMCA, it was left unmodified so that it would remain consistent with SIMCA calculations that are commercially available. SIMCA and FOAM tended to perform complementarily with one furnishing higher specificity while the other yielded higher sensitivity.

FIMS had the best performance with a $96.7 \pm 0.2 \%$ average sensitivity and an average specificity of $86.7 \pm 0.1 \%$ using FOAM. The SIMCA results were slightly worse with $91.1 \pm 0.2 \%$ and $85.7 \pm 0.1 \%$ average sensitivity and specificity, respectively. For NMR, the FOAM average sensitivity and specificity were $91.0 \pm 0.3 \%$ and $78.5 \pm 0.6 \%$, respectively. For SIMCA, the average specificity of $85.7 \pm 0.1 \%$ was greater than the average sensitivity of $77.7 \pm 0.3 \%$. NMR was at a slight disadvantage because fewer spectra were available for building statistical models. These results for the specificities are not so bad when one considers that the A. rubra and A. pachypoda species only contained two samples each and neither the FOAM nor the SIMCA models were optimized in any way.

The relationship between sensitivity and specificity is dependent on the confidence limit or criterion for group membership that can be controlled to favor the sensitivity or specificity of the model. The 95\% confidence interval, which is the red horizontal dashed lines in Fig. 5 A, B, is an example of the model acceptance criterion. A useful approach to evaluate a model is the receiver operating characteristic (ROC) curve, which plots the sensitivity with respect to the false positive rate (i.e., 1-specificity) as a function of the models acceptance criterion [31,32].

The bootstrap Latin partition results were saved to generate the average ROC curves in $\bullet$ Fig. 6 . The best compromise of the sensitivity-specificity tradeoff occurs at the point along the curve closest to the upper left hand corner. By visual inspection one can see that this point corresponds to $90 \%$ sensitivity and $90 \%$ specificity. In general, FOAM appears to perform a little better that SIMCA. It is not possible to directly compare MS and NMR because much fewer samples were analyzed by NMR.

Two classification methods, PLS-DA and FuRES, were compared. As with the modeling evaluation, the FIMS spectra for $A$. racemosa were partitioned by sample (multiples of five spectra) to be comparable to the partitioning of the NMR spectra. The average classi- fication results of the bootstrapped Latin partitions are reported in - Table 5. As mentioned in the introduction, classification is a targeted analysis that, in this case, assigns spectra or fingerprints to one of four classes (A. cimicifuga, A. podocarpa, A. racemosa, and $A$. rubra). Specificity, defined as the correct identification for species other than Racemosa, is challenging because two of these species had only two samples, and the third species only had three samples. Therefore, models were built from one sample and applied to recognize the other samples of the same species for three of the classes, A. pachypoda, A. rubra, and A. podocarpa. Average classification results in Table 5 indicate that PLS-DA and FuRES are comparable for both FIMS and NMR. In this case, when one classifier yielded a greater sensitivity, the other classifier gave a greater specificity. The sensitivities were all above $95 \%$ for FIMS and NMR. The specificities were lower and ranged between $60-70 \%$, which was not surprising with the small sample sizes for the non-A. racemosa spectra. Classification is most effective if the populations of each class are equal. Despite the excellent sensitivity, the two smallest classes, A. pachypoda and A. rubra, were misclassified (data not shown). These data emphasize the importance of having large representative sets of samples for classifier construction.

- Fig. 7 presents the influence models for FIMS and NMR based on the SIMCA for the same A. racemosa samples used in $\bullet$ Fig. 5 to test commercial Asian root samples ( Table 4, CA01 to CA14). The samples were purported to be A. racemosa, A. heracleifolia, $A$. foetida, and $A$. dahurica. In $\odot$ Fig. 6, all of the commercial sample scores are above the $95 \%$ Q confidence limit, even the sample of $A$. racemosa. All the samples were subjected to DNA sequencing. Seven of the samples were identified as A. dahurica, including the sample purported to be $A$. racemosa. DNA sequencing identified one of the samples as A. brachycarpa and four of the samples were other plant materials. All of the samples were a mixture of materials and two could only be identified as a yeast (Pichia spec.) and a fungi (Erotium spec.).

- Fig. 8 again uses the same influence SIMCA plots for FIMS and NMR as $\bigcirc$ Fig. 5 to test 14 commercial supplements of $A$. racemosa purchased from local stores ( Table 4, CS01 to CS14). Two were tablets, seven were capsules, and five were in liquid form. All the supplements, with the exception of one capsule (by both FIMS and NMR), were differentiated from $A$. racemosa root at the 95\% Q confidence level. Most likely, this capsule (CSO9) contained powdered $A$. racemosa root as DNA sequencing confirmed the presence of $A$. racemosa DNA.

A SIMCA model was constructed based on the NIST extracted SRMs (3297 and 3298). Since the SRM materials were obtained from a commercial source that used standard methods for their preparation, it was hypothesized that they would serve as a suitable model for the commercial samples. However, all the commercial supplements were excluded from the model at the $95 \%$ confidence level (data not shown). This result indicates that the different preparations of the SRMs and the commercial supplements have resulted in different chemical fingerprints. This result 

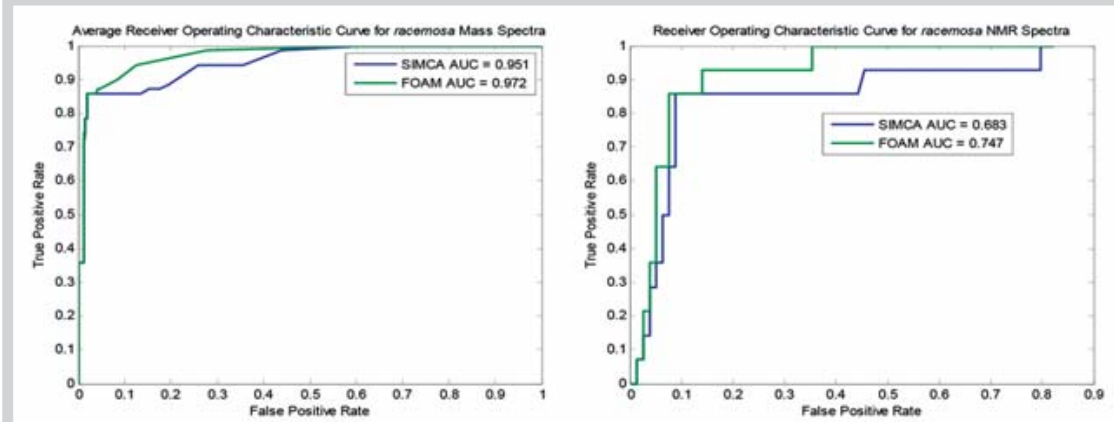

Fig. 6 Average receiver operating curves for $100 \times 4$ bootstrapped Latin partitions that averaged 100 sensitivities and 400 specificities for the MS and NMR modeling evaluations that were built with the racemosa $A$. racemosa data. (Color figure available online only.)
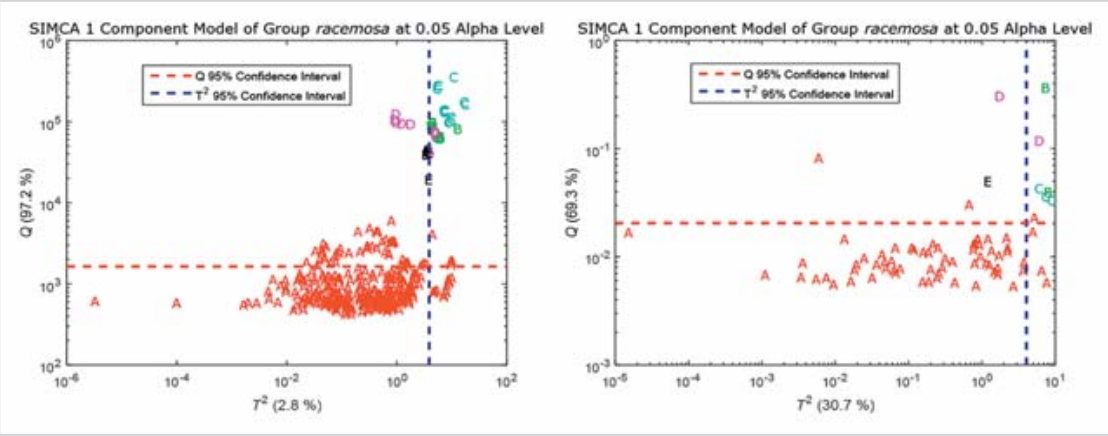

Fig. 7 Influence plots of commercial species on a model built from the $A$. racemosa one component SIMCA reference model. Mass spectra (left) and NMR spectra (right). A (red) A. racemosa, B (green) A. cimicifuga, C (cyan) A. dahurica, D (magenta) A. heracleifolia, $\mathbf{E}$ (black) commercial A. racemosa. (Color figure available online only.)

does not preclude the presence of $A$. racemosa extract in the supplements.

DNA sequencing showed that four of the seven capsules contained DNA from A. racemosa. One contained A. brachycarpa DNA and two contained no Actaea DNA. Of the latter, one had no DNA at all and the other had only rice DNA (Oryza sativa L.; Poaceae), presumably from a rice excipient. Five of the seven showed no indications of a mixture, indicating that the excipient was a refined chemical component, such as a crystalline starch, with no DNA present. None of the liquid supplements were subjected to DNA sequencing as it was assumed there would be no DNA present. These data suggest that a more rigorous metabolomics study is necessary to verify the presence of specific $A$. racemosa marker compounds in the supplements.

In summary, FIMS and NMR produced metabolic fingerprints that were equally capable of discriminating between Actaea species and authenticating $A$. racemosa when looking at raw materials. DNA sequencing of the root materials could be used to identify species and was useful in validating anomalies in the clusters observed by both metabolic fingerprinting methods. FIMS and NMR detected differences between sources of samples of A. racemosa, suggesting systematic geographical and/or processing differences. All three methods demonstrated that none of the tested commercially available root samples were $A$. racemosa. FIMS and NMR fingerprints indicated that commercially available supplements were not similar to any of the raw Actaea materials, suggesting that preparation produced significantly different metabolic profiles. DNA sequencing was successful for identifying four of the seven supplements tested as A. racemosa. The others were a different species or had no DNA present. Receiver operating characteristic curves are useful for evaluating and optimizing authentication models of complex data sets.

\section{Materials and Methods}

Actaea samples

Root materials from various species of Actaea, some vouchered, were collected from four reliable sources and from a variety of commercial sources (Tables 1-4). The sources of samples were the American Herbal Pharmacopoeia (AHP; samples BCR01 to BCR24 in Table 1), Strategic Sourcing, Inc. (SSI; samples SS01 to SS07 in Table 2), The North Carolina Arboretum Germplasm Repository (TNCAGR; samples NCC1, NCC2, and NC01 to NC22 in - Table 3), and the National Institutes of Standards and Technology (NIST; samples SRM 3295, 3296, 3297, and 3298 in $\odot$ Table 2). Commercial root samples were purchased from the Internet and local stores in China (samples CA01 to CA14 in $\odot$ Table 4). Commercial liquid, tablet, and capsule supplements were purchased from local stores in Maryland (CS01 to CS14). TNCAGR samples were collected from the permanent national A. racemosa germplasm collection in collaboration with the USDA NPGS (National Plant Germplasm System).

\section{DNA sequencing}

All root materials and finished products were authenticated using validated DNA sequencing authentication methods for Actaea [29] at AuthenTechnologies LLC. The methods utilized consisted of the extraction of total genomic DNA using a modified silicaspin column approach (Qiagen, Inc.). Next, the nuclear (ITS) and chloroplast (psbA-trnH) genes validated by the National Institute of Standards and Technology [29] for black cohosh identification were amplified using a polymerase chain reaction (PCR) machine using standard cycling parameters. The PCR products were visualized using an E-Gel (Invitrogen) apparatus and visualized using a blue LED box. Positive PCR products were then sequenced on a Sanger sequencing (capillary electrophoresis) machine (Applied Biosystems). The resultant sequence from both the forward and 

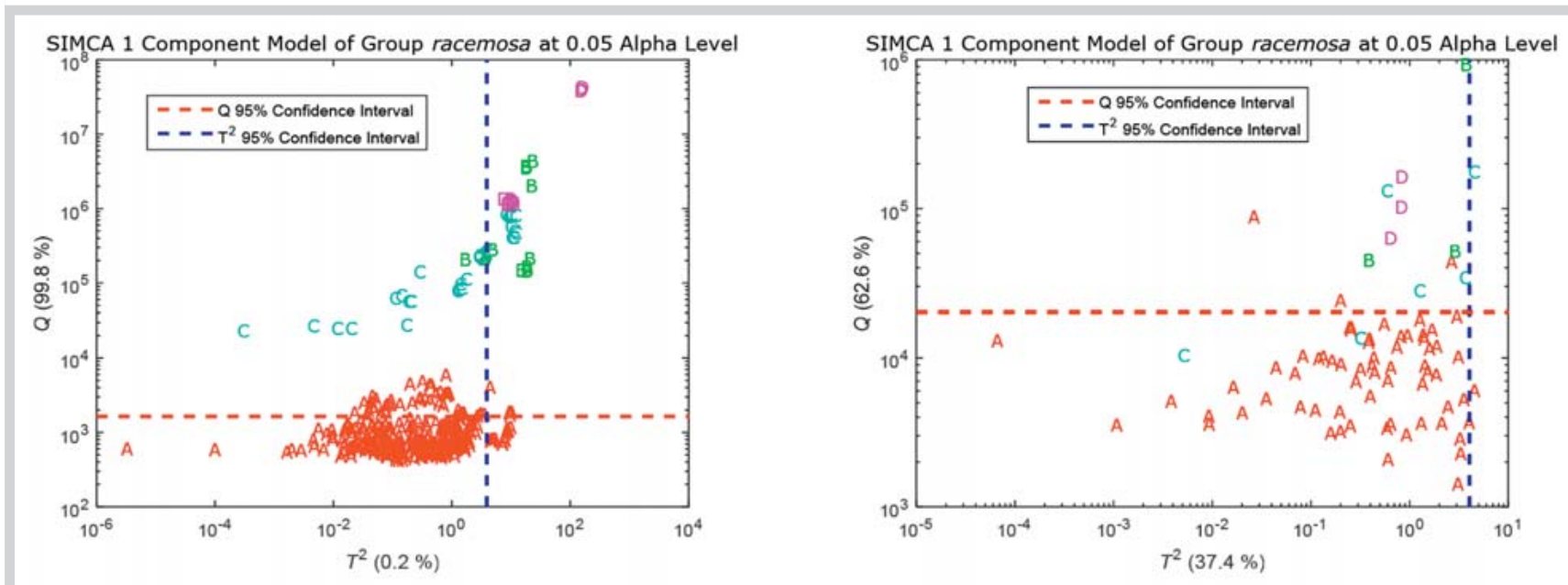

Fig. 8 Influence plots of the A. racemosa SIMCA model with respect to different supplement forms. A (red) root, B (green) tablet, C (cyan) capsule, and D (magenta) liquid. (Color figure available online only.)

reverse directions was assembled into contigs. Overlapping bases indicative of hybrids were scored using standard IUPAC codes. The final assembled sequences were then aligned in a matrix by eye and compared to reference sequences obtained from authenticated herbarium vouchers for the target and closely related nontarget species of Actaea.

\section{Mass spectrometry sample preparation}

Root samples were ground into fine powders. Ten mg of each sample were mixed with $5 \mathrm{~mL}$ of methanol-water $(70-30, v / v)$ in $15 \mathrm{~mL}$ centrifuge tubes and sonicated for $60 \mathrm{~min}$ at room temperature. The extracted samples were centrifuged at $5000 \times \mathrm{g}$ for 10 min (IEC Clinical Centrifuge, Danon/IEC Division). The supernatant was diluted 1 to $10(\mathrm{v} / \mathrm{v})$ with methanol and filtered through a $17-\mathrm{mm}(0.45 \mu \mathrm{m})$ PVDF syringe filter (VWR) prior to injection. To avoid errors arising from unexpected degradation of some compounds, the sample analysis was completed within $24 \mathrm{~h}$ of the extraction. Tablets were prepared the same as root samples. Capsules were opened and the contents were emptied onto a weighing paper. Ten $\mathrm{mg}$ were mixed with $5 \mathrm{~mL}$ of methanol-water $(70-30, v / v)$ in a $15-\mathrm{mL}$ centrifuge tube and then treated in the same manner as the root samples. Ten $\mu \mathrm{L}$ of liquid supplement were mixed with $5 \mathrm{ml}$ of methanol-water $(70-30, \mathrm{v} / \mathrm{v})$ in a $15-\mathrm{mL}$ centrifuge tube and then treated in the same manner as the root samples.

\section{Nuclear magnetic resonance sample preparation}

Aliquots of the samples prepared in methanol-water for analysis by FIMS were taken to dryness for transportation to the Bruker Bio-Spin laboratory. Samples were prepared for NMR by dissolving $25 \mathrm{mg}$ of each dried sample in $1.0 \mathrm{~mL}$ of DMSO- $d_{6}$ containing $0.47 \mathrm{mM}$ DSS to provide a final concentration of $25 \mathrm{mg} / \mathrm{ml}$. Each sample was vortexed for $1 \mathrm{~min}$ and sonicated for $5 \mathrm{~min}$. The samples were then centrifuged for $15 \mathrm{~min}$ at $13500 \mathrm{rpm}$ (Eppendorf $5810 \mathrm{R}$, Eppendorf AG) to remove any undissolved materials. Then, $600 \mu \mathrm{L}$ of the supernatant was transferred to a 5-mm NMR tube (Wilmad PP-5 and Bruker Z107374) for spectroscopy.

\section{Mass spectrometry instrumentation}

The FIMS system consisted of a Q Exactive mass spectrometer (Thermo Fisher Scientific) with an Agilent 1200 HPLC system (a quaternary pump with a vacuum degasser, a thermostated column compartment, an autosampler, and a diode array detector). The flow injection used a guard column (Adsorbosphere AllGuard Cartridge, C18, $5 \mu \mathrm{m}, 4.6 \times 7.5 \mathrm{~mm}$, Alltech Associates, Inc.) to minimize potential contamination of the FIMS system. Mobile phases consisted of $0.1 \%$ formic acid in $\mathrm{H}_{2} \mathrm{O}$ (A) and $0.1 \%$ formic acid in acetonitrile (B) with isocratic elution at $50: 50(\mathrm{v} / \mathrm{v})$ at a flow rate of $0.5 \mathrm{~mL} / \mathrm{min}$ for $2 \mathrm{~min}$. Electrospray ionization was performed in the negative ion mode from $m / z$ 150-1500 to obtain the FIMS fingerprints. The following conditions were used for the mass spectrometer: sheath gas flow rate, 80 (arbitrary units); aux gas flow rate, 10 (arbitrary units); spray voltage, $4.50 \mathrm{kV}$; heated capillary temperature, $220^{\circ} \mathrm{C}$; capillary voltage, $4.0 \mathrm{~V}$; tube lens offset, $25 \mathrm{~V}$. The injection volume for all samples was $10 \mu \mathrm{L}$.

\section{Nuclear magnetic resonance instrumentation}

All NMR experiments were performed with a Bruker AVANCE III spectrometer $(600.13 \mathrm{MHz})$ at $298 \mathrm{~K}$ with a Bruker 5-mm TCI CryoProbe. Spectra were collected using the software program TopSpin 3.1 (Bruker BioSpin). One-dimensional proton nuclear Overhauser effect spectroscopy with an inverse gated decoupling pulse sequence (noesyigld $1 \mathrm{~d}$ ) using a base opt filter was performed using 64 scans, four dummy scans, and 65536 data points. A relaxation delay of $10 \mathrm{~s}$ with a mixing time of $0.01 \mathrm{sec}-$ onds was used to allow an acquisition time of $14 \mathrm{~min}$ for each experiment.

\section{Sample analysis}

The sequence of the samples was randomized for both FIMS and NMR. For FIMS, each sample in $\odot$ Tables 1-4 (with the exception of BCR21 which was not run) was run five times for a total of 1140 analyses. After running each sample once in random order, a new random sequence of measurements was made. Spectra were summed over the $1.0 \mathrm{~min}$ interval from $0.5 \mathrm{~min}$ to $1.5 \mathrm{~min}$ of the sample bolus. 
For NMR, each sample was run only once. Exceptions were BCR03 and BCR21, which were not run, and BCR02 and BCR16, which were analyzed twice. Each of the second analyses was on a separate day two weeks later to check for possible mislabeling of the samples. This sampling provided a total of 130 analyses. The NMR spectra were acquired from -3.0 to $16.0 \mathrm{ppm}$, but only the region from 0.5 to $9.0 \mathrm{ppm}$ was used in this study.

\section{Mass spectrometry data processing}

The FIMS fingerprints of each sample were mass spectra, i.e., ion counts with respect to the mass-to-charge ratio for a range of $\mathrm{m} / \mathrm{z}$ 150 to 1500. The spectra were exported as Excel files (Microsoft, Inc.) for data preprocessing and then imported into either Solo (Eigenvector Research, Inc.), for principal component analysis (PCA) and soft independent modeling of class analogy (SIMCA), or to MATLAB 2014a (MathWorks) for classification and validation studies.

\section{Nuclear magnetic resonance data processing}

The NMR fingerprints for each sample were spectra, i.e., signal intensity with respect to chemical shift from $0.5 \mathrm{ppm}$ to $9.0 \mathrm{ppm}$. The spectra were exported as Excel files and then imported into Solo or MATLAB 2014a. Prior to preprocessing, the solvent peaks were removed at $2.53 \mathrm{ppm}$ (DMSO) and $3.19 \mathrm{ppm}$ (methanol) by excising the respective ranges $2.51-2.56 \mathrm{ppm}$ and $3.18-3.21 \mathrm{ppm}$ from all of the spectra.

\section{Chemometrics}

The same processing was used for the FIMS and NMR data. The spectra were normalized to unit vector length (i.e., the sum of the squares of the data points for each spectrum was unity), autoscaled, and mean-centered prior to PCA or SIMCA.

\section{Classifiers}

There are two general types of classifiers: modeling (soft modeling or one-class classifiers) and classification (hard modeling or multiclass classifiers). The first category comprised SIMCA [22] and FOAM [23] and the latter comprised PLS-DA [24] and FuRES [25]. All four approaches (SIMCA, FOAM, PLS-DA, and FuRES) were applied to the data in this study.

SIMCA models were constrained to a single component. FOAM was used with standard parameters for the fuzzy grid encoding. The grid size was 100 and a 19-point triangular fuzzy membership function was applied to the intensities of the FIMS and NMR spectra. Both SIMCA and FOAM used the Q statistic to determine the fit to the model at a $95 \%$ confidence interval. A simple empirical method set the boundary condition to distance that would exclude $5 \%$ of the objects in the calibration set. FOAM, however, uses an internal bootstrap Latin partition to determine the average residual error for the objects in the calibration set. The boundary condition was calculated from the average residual errors. FOAM was later modified to estimate the error by partitioning by sample as opposed to spectrum, because the internal bootstrap was underestimating the error. A similar approach could be used with SIMCA and the results would be similar. Note that the internal bootstrap error estimation is only applied to the training set of data.

A self-optimizing version of PLS-DA was used. This method applies a bootstrap Latin partition [33] to the calibration data set and determines the number of components (i.e., latent variables) that minimizes the average prediction error across the bootstraps. For all cases, the calibration data was divided into two partitions and averaged ten times within the PLS-DA computation. A model is constructed using the entire calibration data with the number of components that achieved the lowest prediction error. There are no adjustable parameters for FuRES, the softness of the model is determined by maximizing the magnitude of the first derivative of the fuzzy entropy of classification with respect to the computational temperature (i.e., discriminant vector length).

\section{Validation}

The NMR data contained two samples for which repeat measurements were made. For the sensitivity and specificity calculations, the replicate samples that were collected last were removed from the evaluation, so that each sample had only a single spectrum in the data set. The FIMS data set had 81 samples while the NMR data set had 77 samples. The FIMS data set was reduced to the same set of 77 samples that were measured by NMR. In addition, both data sets were reduced to subsets of 20 samples that corresponded to samples obtained from AHP. Validation was accomplished by partitioning the data by sample, so that all five replicates of the same sample would be in either the calibration set or prediction set. This mode allows the FIMS results to be compared with the NMR results. In addition, this method is more rigorous and assesses the performance to generalize to new samples, which is most typically encountered in practical applications.

Prior to classification the principal component transform (PCT) [34], which is a form of lossless compression, was applied to the data to increase the speed for FuRES and PLS-DA. For each bootstrap, the principal components were constructed from the calibration data, and then the prediction data were projected onto those same components. The PCT was unnecessary for SIMCA and FOAM because both of these methods are computationally very fast.

\section{Pooled analysis of variance}

This method has been previously described [10]. In brief, classic ANOVA is performed for every variable in the MS or NMR spectra and the resulting ratios are pooled to obtain an overall $\mathrm{F}$ value.

\section{Acknowledgements}

$\nabla$

This research is supported by the Agricultural Research Service of the U.S. Department of Agriculture and an Interagency Agreement with the Office of Dietary Supplements of the National Institutes of Health.

\section{Conflict of Interest \\ $\nabla$}

The authors declare no conflicts of interest.

\footnotetext{
Affiliations

${ }^{1}$ Food Composition and Methods Development Laboratory, Beltsville Human Nutrition Research Center, Agricultural Research Service, U. S. Department of Agriculture, Beltsville, MD, USA

2 Bruker BioSpin, Billerica, MA, USA

${ }^{3}$ The North Carolina Arboretum Germplasm Repository, Asheville, NC, USA

${ }^{4}$ AuthenTechnologies LLC, Richmond, CA, USA

${ }^{5}$ Center for Intelligent Chemical Instrumentation, Department of Chemistry and Biochemistry, Clippinger Laboratories, Ohio University, Athens, OH, USA ${ }^{6}$ Strategic Sourcing, Inc., Banner Elk, NC, USA
} 


\section{References}

1 Blumenthal M. Herb sales down 7.4 percent in mainstream market; garlic is top-selling herb; herb combinations see increase. HerbalGram 2005; 66: 63

2 Hildreth J, Hrabeta-Robinson E, Applequist W, Betz L. Standard operating procedure for the collection and preparation of voucher plant specimens for use in the nutraceutical industry. Anal Bioanal Chem 2007; 389: $13-17$

3 Hall RD. Plant metabolomics from holistic hope, to hype, to hot topic. New Phytol 2006; 169: 453-468

4 AOAC International; Guideline Working Group. AOAC INTERNATIONAL guidelines for validation of botanical identification methods. J AOAC Int 2012; 95: 268-272

5 LaBudde R, Harnly JM. Probability of identification (POI): a statistical model for the validation of qualitative botanical identification methods. J AOAC Int 2012; 95: 273-285

6 Ma C, Kavalier AR, Jiang B, Kennelly EJ. Metabolic profiling of Actaea species extracts using high performance liquid chromatography coupled with electrospray ionization time-of-flight mass spectrometry. J Chromatogr A 2011; 1218: 1461-1476

7 Qiu F, McAlpine JB, Lankin DC, Burton I, Karakach T, Chen SN, Pauli GF. 2D NMR barcoding and differential analysis of complex mixtures for chemical identification: the Actaea terpenes. Anal Chem 2014; 86: 3964-3972

8 Masada-Atsumi S, Kumeta Y, Takahashi Y, Hakamatsuka T, Goda Y. Evaluation of the botanical origin of black cohosh products by generic and chemical analyses. Biol Pharm Bull 2014; 37: 454-460

9 He K, Pauli GF, Zheng B, Wang H, Bai N, Peng T, Roller M, Zheng Q. Cimicifuga species identification by high performance liquid chromatography-photodiode array/mass spectrometric/evaporative light scattering detection for quality control of black cohosh products. J Chromatogr A 2006; 1112: 241-254

10 Harnly JM, Harrington PB. Adulteration of American with Asian ginseng: spectral addition and experimental verification of probability of identification. J AOAC Int 2013; 96: 1258-1265

11 Harnly JM, Luthria DL, Chen P. Detection of adulterated Ginkgo biloba supplements using chromatographic and spectral fingerprints. J AOAC Int 2012; 95: 1579-1587

12 Harnly JM, Mukhopadhyay S, Lin LZ, Luthria DL. A comparison of analytical and data preprocessing methods for spectral fingerprinting. Appl Spectrosc 2011; 65: 250-259

13 Luthria DL, Lin LZ, Robbins RJ, Finley JW, Banuelos GS, Harnly JM. Discriminating between cultivars and treatments of broccoli using mass spectral fingerprinting and analysis of variance principal component analysis. J Agric Food Chem 2008; 56: 9819-9827

14 Chen P, Luthria D, Harrington PB, Harnly JM. Discrimination among Panax species using spectral fingerprinting. J AOAC Int 2011; 94: 1411-1421

15 Huang H, Sun J, McCoy JA, Zhong H, Fletcher EJ, Harnly JM, Chen P. Use of flow injection mass spectrometric fingerprinting (FIMS) and chemometrics for differentiation of three black cohosh species. Spectrochim Acta 2014, in press

16 Chen P, Sun J, Ford P. Differentiation of the four major species of cinnamons (C. burmannii, C. verum, C. cassia, and C. loureiroi) using a flow injection mass spectrometric (FIMS) fingerprinting method. J Agric Food Chem 2014; 62: 2516-2521
17 Safer S, Cicek A, Pieri V, Schwaiger P, Schneider P, Wissemann V, Stuppner $H$. Metabolic fingerprinting of Leontopodium species (Asteraceaea) by means of ${ }^{1}$ H-NMR and HPLC-ESI-MS. Phytochemistry 2011; 72: 1379-1389

18 Yilmaz A, Nyberg N, Mølgaard P, Asili J, Jaroszewski J. ${ }^{1} \mathrm{H}$ NMR metabolic fingerprinting of saffron extracts. Metabolomics 2010; 6: 511-517

19 Ali K, Maltese F, Zyprian E, Rex M, Choi YH, Verpoorte R. NMR metabolic fingerprinting based identification of grapevine metabolites associated with downy mildew resistance. J Agric Food Chem 2009; 57: 95999606

$20 \mathrm{Kim}$ HY, Choi YH, Erkelens C, Lefeber AW, Verpoorte R. Metabolic fingerprinting of Ephedra species using ${ }^{1} \mathrm{H}-\mathrm{NMR}$ spectroscopy and principal component analysis. Chem Pharm Bull (Tokyo) 2005; 53: 105-109

21 Kim HK, Saifullah, Khan S, Wilson EG, Kricun SD, Meissner A, Goraler S, Deelder AM, Choi YH, Verpoorte R. Metabolic classification of South American Ilex species by NMR-base metabolomics. Phytochemistry 2010; 71: 773-784

22 Wold S. Pattern-recognition by means of disjoint principal components models. Pattern Recogn 1976; 8: 127-139

23 Wabuyele BW, Harrington PD. Fuzzy optimal associative memory for background prediction of near-infrared spectra. Appl Spectrosc 1996; 50: $35-42$

24 Harrington PB, Kister J, Artaud J, Dupuy N. Automated principal component-based orthogonal signal correction applied to fused near infrared-mid-infrared spectra of French olive oils. Anal Chem 2008; 81: 7160-7169

25 Harrington PB. Fuzzy multivariate rule-building expert systems - minimal neural networks. J Chemometr 1991; 5: 467-486

26 CBOL Plant Working Group. A DNA barcode for land plants. Proc Natl Acad Sci U S A 2009; 106: 12794-12797

27 Gafner S, Blumenthal M, Reynaud DH, Foster S, Techen N. ABC review and critique of the research article "DNA barcoding detects contamination and substitution in North American herbal products" by Newmaster et al. HerbalEGram 2013; 10: 11

28 Reynaud D, Handy S. Primers for short DNA sequences. AuthenTechnologies, LLC and US Food and Drug Administration. Personal communication; 2015

29 Reynaud D. DNA sequencing of SRM 3295, Actaea racemosa. AuthenTechnologies, LLC, Personal communication; 2014

30 Strobel G, Daisy B. Bioprospecting for microbial endophytes and their natural products. Microbiol Mol Biol Rev 2003; 67: 491-502

31 Genazzani $A D$, Rodbard $D$. Use of the receiver operating characteristic curve to evaluate sensitivity, specificity, and accuracy of methods for detection of peaks in hormone time-series. Acta Endocrinol (Copenh) 1991; 124: 295-306

32 Hanley JA, Mcneil BJ. The meaning and use of the area under a receiver operating characteristic (Roc) curve. Radiology 1982; 143: 29-36

33 Harrington $P D B$. Statistical validation of classification and calibration models using bootstrapped Latin partitions. Trends Anal Chem 2006; 25: $1112-1124$

34 Sun XB, Zimmermann CM, Jackson GP, Bunker CE, Harrington PB. Classification of jet fuels by fuzzy rule-building expert systems applied to three-way data by fast gas chromatography-fast scanning quadrupole ion trap mass spectrometry. Talanta 2011; 83: 1260-1268 